\title{
The Effect of Parasitic Rings and Ground Plane on Helix Strip Antenna
}

\author{
Muchammad Rofiq Fajar Setiawan ${ }^{1}$, Aryo Baskoro Utomo ${ }^{2}$
}

\begin{abstract}
Strip helix antennas offer better performance at wide bandwidth and more compact in size than conventional helix antennas. However, strip helix antennas have a relatively low gain compared to conventional helix antennas. In this paper, a strip helix antenna with $2.4 \mathrm{GHz}$ frequency was designed, simulated, fabricated, and measured. This strip helix antenna was added with several parasitic rings, and its ground plane size was reduced to increase the gain value and its performance. The best simulation results according to the desired parameters were with return loss $<-10 \mathrm{~dB}$ of $-10.366 \mathrm{~dB}$, VSWR $<2$ of 1.8702 , and directional radiation pattern of $66.5^{\circ}$ beamwidth angle. However, the gain did not match with the desired parameters $>12 \mathrm{~dB}$ with the result of $8.9612 \mathrm{~dB}$. Measured results showed that the helix strip antenna has a return loss of $\mathbf{- 1 0 . 3 7} \mathrm{dB}$ and VSWR of 1.870. The parasitic rings addition can increase the strip helix antenna gain of 0.0201 $\mathrm{dB}$ and improves performances of return loss, VSWR, and bandwidth. Despite that, the ground plane size reduction actually decreases the gain value.
\end{abstract}

Keyword-Helix Strip Antenna, Parasitic Ring, Ground Plane, Gain.

\section{INTRODUCTION}

Telecommunications is a technique for delivering information from one place to another. One technique for delivering information is through a wireless network called wireless telecommunications. Wireless telecommunications allow for more comfortable use compared to the use of cable telecommunications networks [1]. Some wireless telecommunication applications are satellite communication, radar, internet, radio, telemetry, and microwave transmissions [2].

Nowadays, wireless telecommunication application is used relatively extensively in the Unmanned Aerial Vehicle (UAV) as in the video transceiver device, i.e., First Person View (FPV). An FPV works using microwave signals with frequency bands at $2.4 \mathrm{GHz}$ and $5.8 \mathrm{GHz}$. This frequency is the recommended standard for video signal transmission [3]. Hence, a helix antenna is one of the antenna types suitable to be applied to FPV devices.

Conventional axial mode helix wire antennas are known to be an antenna type with an excellent circular polarization performance [4]. It has a directional radiation pattern and circularly polarized waves when the helix circumference is greater than its wavelength [5]-[7]. However, this helix antenna is not compact when applied to mobile devices such as FPV

1,2 Department of Electrical Engineering Universitas Negeri Semarang, Kampus Sekaran, Gunungpati, Semarang 50229 INDONESIA (phone: 024-8508104; fax: 024-8508009; e-mail: muchammadrofiqfajarsetiawan@students.unnes.ac.id, aryobaskoro@mail.unnes.ac.id) because its size is too large and wide. Some studies have been carried out to overcome this helix antenna size issue, such as the use of parasitic circular rings [8], the merging of helix antennas with patches [9], conical strip helix antennas [10], 1 , 1 turn vertical strip helix antennas [11], and horizontal strip helix antennas with the addition of parasitic patches [12].

In a study that has been carried out [12], the designed 1.5 $\mathrm{GHz}$ helix antennas have the widest bandwidth compared to other studies [10], [11], [13]-[18]. This helix antenna size was also more compact than other antennas. However, the antenna in that study still used a wide ground plane. The produced gain was still small, which was $9.4 \mathrm{~dB}$, smaller than the gain in other studies, which were $12.5 \mathrm{~dB}$, and $13 \mathrm{~dB}$ [9]. Therefore, an increase is still needed so that the produced gain is more significant with a more compact size.

This paper discussed the design of a $2.4 \mathrm{GHz}$ strip helix antenna. The utilized antenna type is the same as the antenna designed in the previous study, i.e., the strip helix antenna with parasitic patch addition [12]. The utilization of parasitic elements is a well-known technique that can increase the gain value on an antenna [8], [19]-[21]. In addition, it has been proven that the ground plane size reduction is able to increase the gain value on the helix antenna [5]. Hence, in this strip helix antenna design, parasitic elements such as parasitic rings [8] and ground plane sizes [5] were added, so that a $2.4 \mathrm{GHz}$ strip helix antenna was expected to be produced with a compact size, wide bandwidth and high gain.

\section{ANTENNA DESIGN PROCEDURES}

The main parameter in designing an antenna is the antenna frequency. This strip helix antenna design used $2.4 \mathrm{GHz}$ frequency with a frequency range of 2.0-2.8 GHz. Other parameters in this antenna design were bandwidth, return loss, VSWR, and radiation pattern. Table I shows the target of antenna parameter specification to achieve, with parameters of VSWR $<2$ and return loss $<-10$ as the recommended references standard for good antenna results.

The antenna design started with a basic calculation based on the main parameters, i.e., the working frequency, to determine the helix antenna dimensions. From the working frequency, the $(\lambda)$ wavelength could be obtained using (1).

$$
\lambda=\frac{c}{f}
$$

where $\lambda$ was the wavelength (m), $c$ was the speed of light in a vacuum $\left(3 \times 10^{8} \mathrm{~m} / \mathrm{s}\right)$, and $f$ was the frequency $(\mathrm{Hz})$.

From (1) a $125 \mathrm{~mm} \lambda$ was produced. This designed helix antenna had an axial mode. In achieving the mode, a circumference $(C)$ of a $\lambda=125 \mathrm{~mm}$ helix antenna was made. 


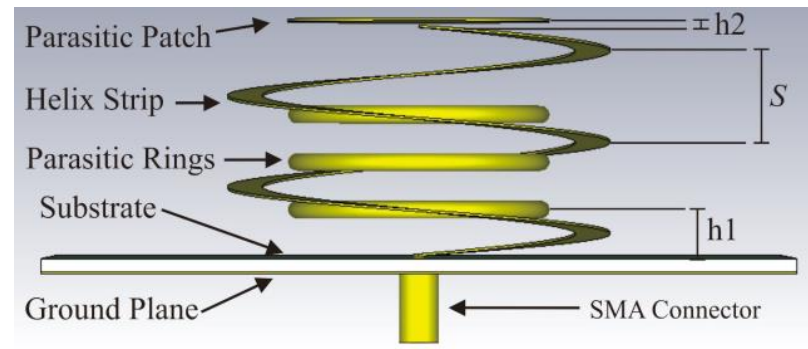

(a)

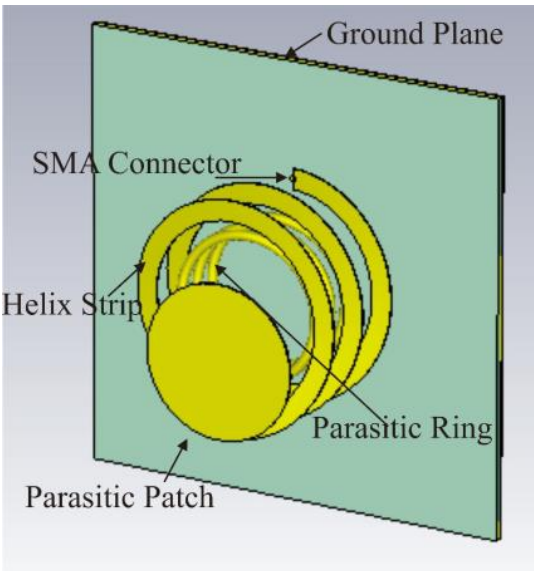

(b)

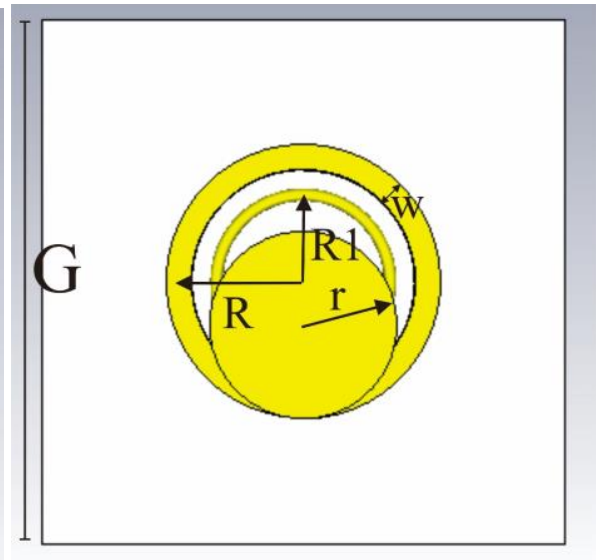

(c)

Fig. 1 Geometry of proposed helix strip antenna with parasitic rings addition and ground plane reduction, (a) side view, (b) perspective view, (c) top view.

TABLE I

DESIRED PARAMETERS

\begin{tabular}{|c|c|c|}
\hline Parameters & Value & Unit \\
\hline Frequency & $2.0-2.8$ & $\mathrm{GHz}$ \\
\hline VSWR & $<2$ & \\
\hline Return loss & $\leq-10$ & $\mathrm{~dB}$ \\
\hline Radiation pattern & Directional & \\
\hline Gain & $>12$ & $\mathrm{~dB}$ \\
\hline
\end{tabular}

Then, the helix radius $(R)$ of $20 \mathrm{~mm}$ could be obtained using (2).

$$
C=2 \pi R
$$

The angle $(\alpha)$ used for this helix antenna was $5^{\circ}$; it referred to the previous study [12]. From this angle, the distance of a $10.9 \mathrm{~mm}$ helix turns $(S)$ could be seen using (3).

$$
S=C \tan \alpha .
$$

The calculation results were implemented using CST Studio Suite software. An optimal design result was obtained from several simulation scenarios including simulation 1 in the form of strip width variations, simulation 2 in the form of turn number variation, simulation 3 in the form of parasitic patch radius variation, simulation 4 in the form of parasitic ring radius variation, and simulation 5 in the form of parasitic ring number variation. The size of the ground plane width $(G)$ used was $0.68 \lambda$, smaller than the previous research design, which was with $G$ of $0.78 \lambda$ [12].

Variations in the utilized strip width were $4 \mathrm{~mm}, 6 \mathrm{~mm}, 8$ $\mathrm{mm}$ and $10 \mathrm{~mm}$. The helix radius $(R)$ was calculated from the helix's midpoint to the strip width's midpoint $(w)$. Next, a simulation was carried out with several turns' variation, i.e., $1.5 ; 2 ; 2.5 ; 3 ; 3.5$; and 4 turns. The simulation started from 1,5 turns because according to previous research, the strip helix antenna cannot produce circular polarization with only 1 turn [11]. Results of the best size from the previous two simulations were used as size references for the next simulations.

The next simulation was a patch addition with parasitic patch radius size variations (r), i.e., $18 \mathrm{~mm}, 17 \mathrm{~mm}, 16 \mathrm{~mm}, 15 \mathrm{~mm}$, and $14 \mathrm{~mm}$. The size represented $90 \%, 85 \%, 80 \%, 75 \%$, and $70 \%$ of the helix radius. The patch was placed on a strip helix loop with a distance $(h 2)$ of $0.5 \mathrm{~mm}$. Then, a parasitic ring with various parasitic ring radius $(R l)$ was added, i.e., $15 \mathrm{~mm}, 14$ $\mathrm{mm}, 13 \mathrm{~mm}$, and $12 \mathrm{~mm}$. Simulation of parasitic ring radius variations was administered to obtain the highest gain value after the addition of the parasitic rings, so as to be able to compare the gain between strip helix antenna with and without parasitic ring addition. The parasitic ring was placed on the substrate with a distance $(h l)$ of $5.45 \mathrm{~mm}$ or $S / 2$, where $S$ was a distance of 1 helix loop. After that, the number of parasitic rings was varied with $1,2,3$, and 4 parasitic rings to find out the best gain by still noticing other antenna parameters.

Fig. 1 shows the geometry of the designed antenna. This strip helix antenna was wrapped to the left direction to produce Left Hand Circular Polarization (LHCP). The ground plane used in this study was made of copper with a substrate layer in the form of FR-4 epoxy, helix strips and parasitic patches made of copper plates with a $0.2 \mathrm{~mm}$ thickness, and parasitic rings made of copper wire with a $2 \mathrm{~mm}$ cross-section diameter. A Printed 


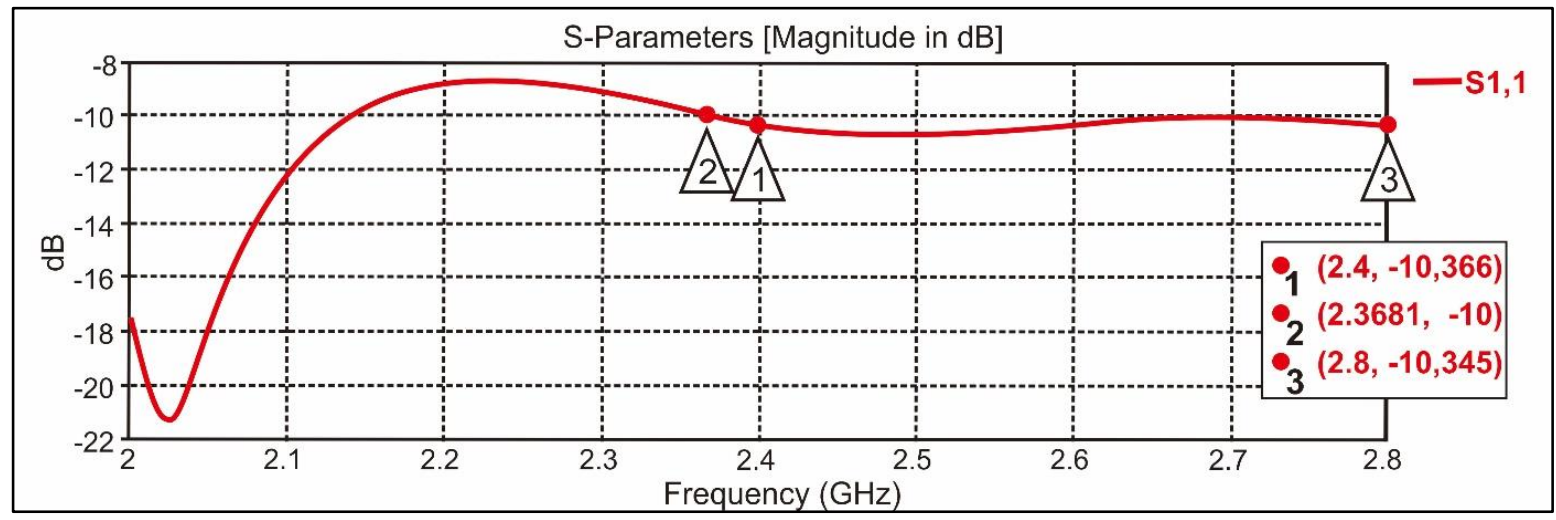

Fig. 2 Return loss and bandwidth.

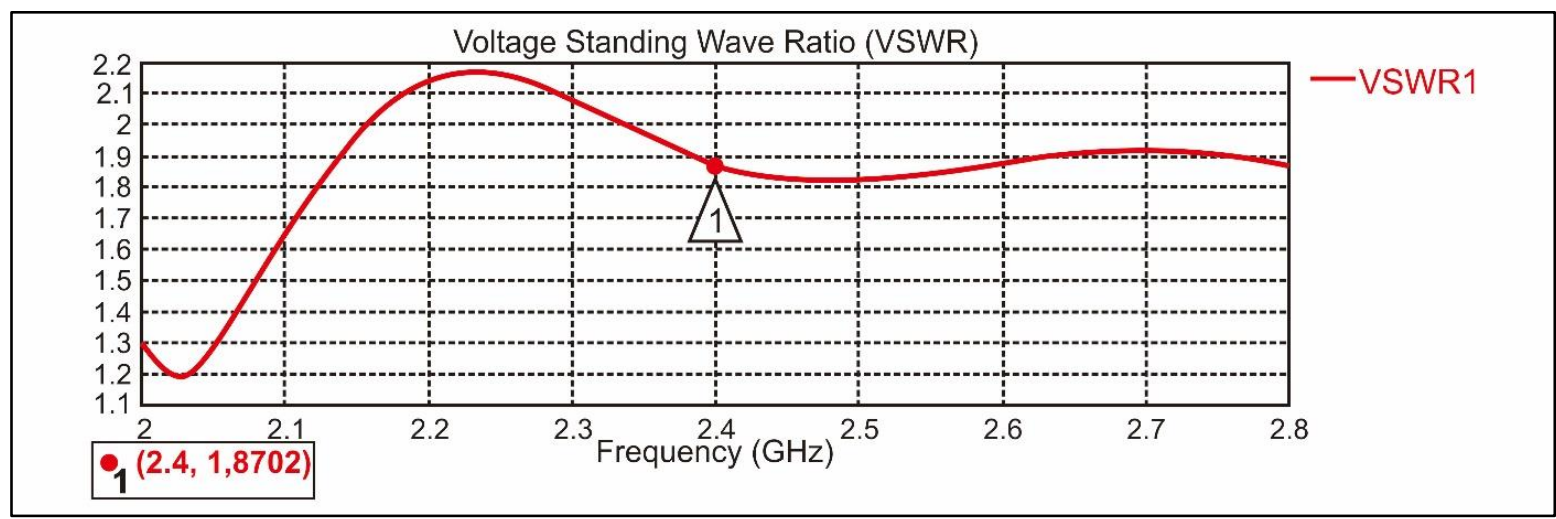

Fig. 3 VSWR.

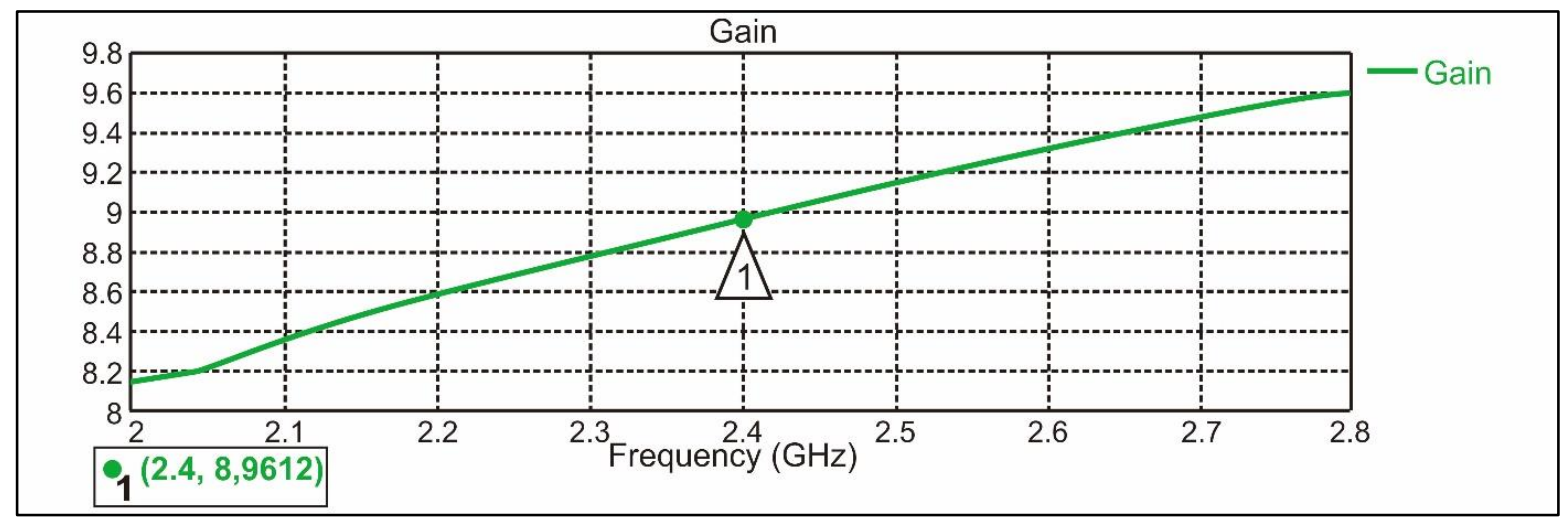

Fig. 4 Gain.

Circuit Board (PCB) material was used for the ground plane and substrate layers to ease the fabrication process.

\section{RESULT AND DISCUSSIONS}

This section analyzes the best antenna design results through simulation without parasitic rings addition, simulation results after parasitic rings addition, and antenna prototype test results. The observed parameters were return loss, VSWR, gain, bandwidth, and radiation patterns.

The performed simulations, simulation 1 to simulation 3, produced the best parameter in the strip helix antenna without the parasitic rings' addition. The generated return loss was $10.169 \mathrm{~dB}$ with a bandwidth of $135.7 \mathrm{MHz}$. The generated gain was $8.9411 \mathrm{~dB}$; the generated VSWR was 1.8991 with a directional radiation pattern. These results indicate that the simulation results are in line with the desired parameters. However, the gain value still does not reach the desired parameter, which is supposed to be $>12 \mathrm{~dB}$.

The parasitic rings addition was performed from simulations 4 and 5. Simulations performed on a helix strip antenna with the parasitic ring addition generated a return loss value of $10.366 \mathrm{~dB}$ with a bandwidth of $431.9 \mathrm{MHz}$, as shown in Fig 2. The Fig. 3 shows the VSWR result of 1.8702, and Fig. 4 shows the generated gain of $8.9612 \mathrm{~dB}$. The radiation pattern shows that a directional pattern is formed with a beamwidth angle of $66.5^{\circ}$, as shown in Fig. 5. It shows that the parasitic ring 


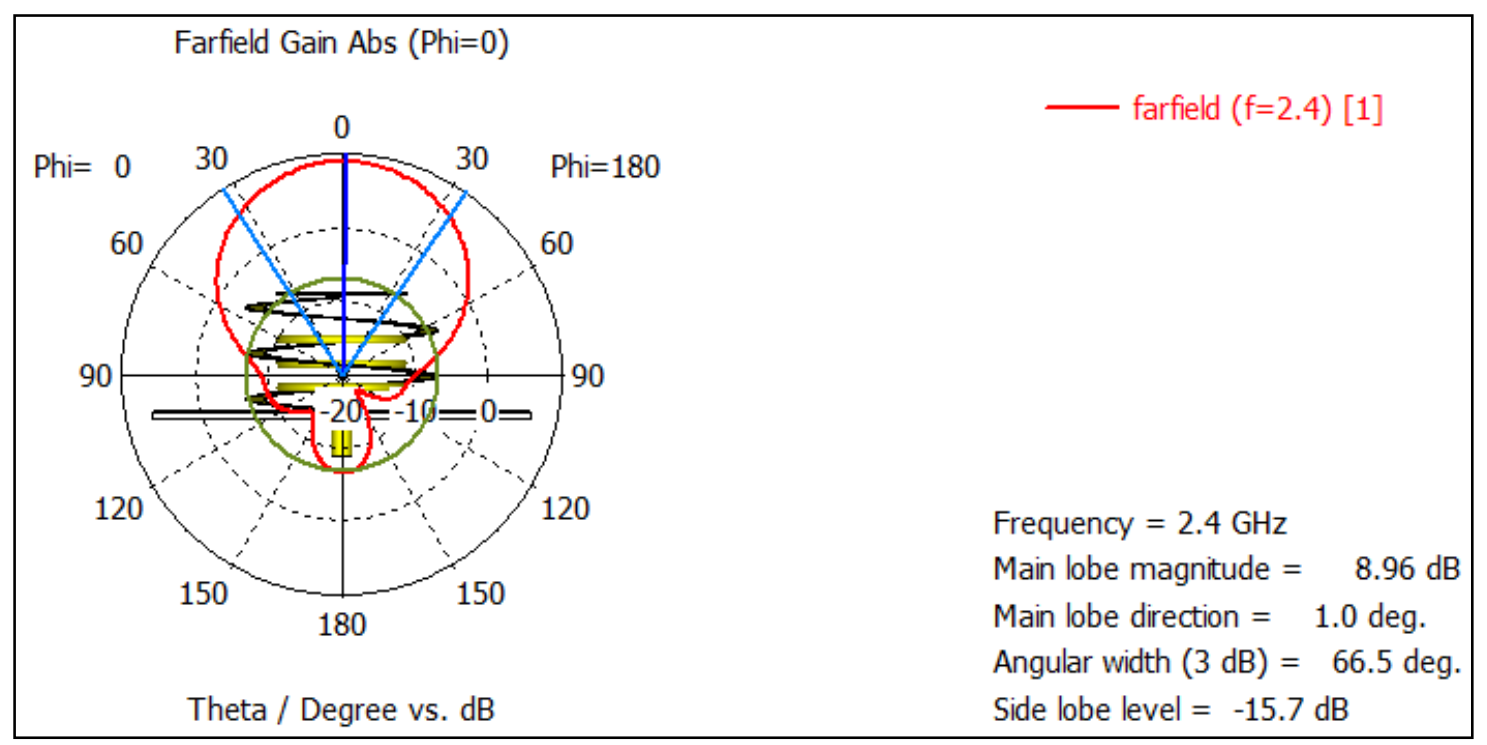

Fig. 5 Radiation pattern.

TABLE II

THE BEST ANTENNA DIMENSION FROM SIMULATION RESULTS

\begin{tabular}{|l|c|}
\hline \multicolumn{1}{|c|}{ Dimension } & Value \\
\hline Helix strip width & $4 \mathrm{~mm}$ \\
\hline Number of turns & $2.5 \mathrm{turns}$ \\
\hline Patch radius & $15 \mathrm{~mm}$ \\
\hline Parasitic ring radius & $14 \mathrm{~mm}$ \\
\hline Number of parasitic rings & 3 pieces \\
\hline
\end{tabular}

addition in the strip helix antenna can increase the return loss, bandwidth, gain, and VSWR values.

The bandwidth generated from the helix strip antenna with parasitic rings addition has increased by $296.2 \mathrm{MHz}$ compared without the parasitic rings' addition. Furthermore, the gain generated from strip helix antenna with parasitic ring addition increased by $0.0201 \mathrm{~dB}$ This is consistent with previous research which states that the parasitic ring addition can increase the gain value on the helix antenna [8]. This study has proven that parasitic rings addition can also increase the gain value in the strip helix antenna. Furthermore, the addition of the parasitic rings can also increase bandwidth and other antenna parameters to a higher degree.

A simulation on ground plane size reduction was also performed in this paper. The ground plane reduction variation was performed by testing the antenna with a ground plane of $0.78 \lambda$ and $0.68 \lambda$. In previous studies, ground plane reduction was able to increase the gain value on conventional helix antennas [5]. However, the ground plane size reduction on the strip helix antenna actually reduces the gain value. A helix strip antenna with a ground plane size of $0.78 \lambda$ generates a gain of $9,134 \mathrm{~dB}$ and an antenna with a ground plane of $0.68 \lambda$ results in a gain of $8.9611 \mathrm{~dB}$. Nevertheless, with a smaller ground plane size, the other generated parameters are better.

The simulation results were used as a reference in making the strip helix antenna prototype with parasitic rings addition. The best antenna dimensions based on the simulation results are shown in Table II. Results of strip helix antenna fabrication

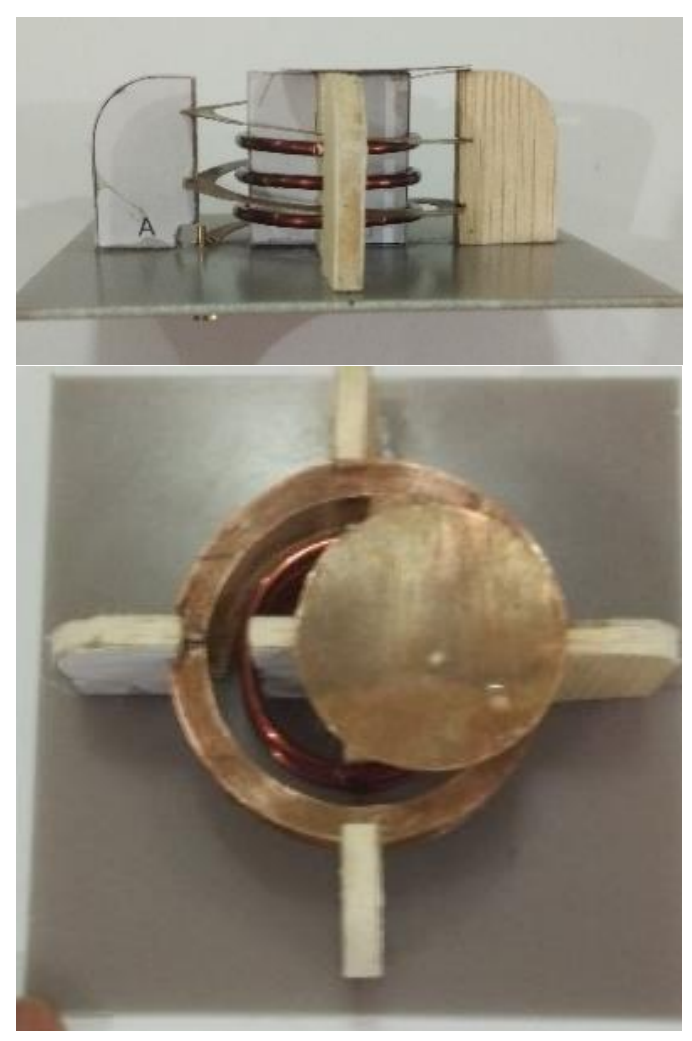

Fig. 6 Prototype of proposed strip helix antenna.

with parasitic rings addition and ground plane reduction are shown in Fig. 6.

The prototype fabrication results were then tested using a network analyzer. The test was administered to find out the parameter values generated by the strip helix antenna prototype including the return loss and VSWR results. The return loss and VSWR tests values were $-10.37 \mathrm{~dB}$, and 1.870 , respectively. The return loss test results are shown in Fig. 7 and the VSWR test results are in Fig. 8. 


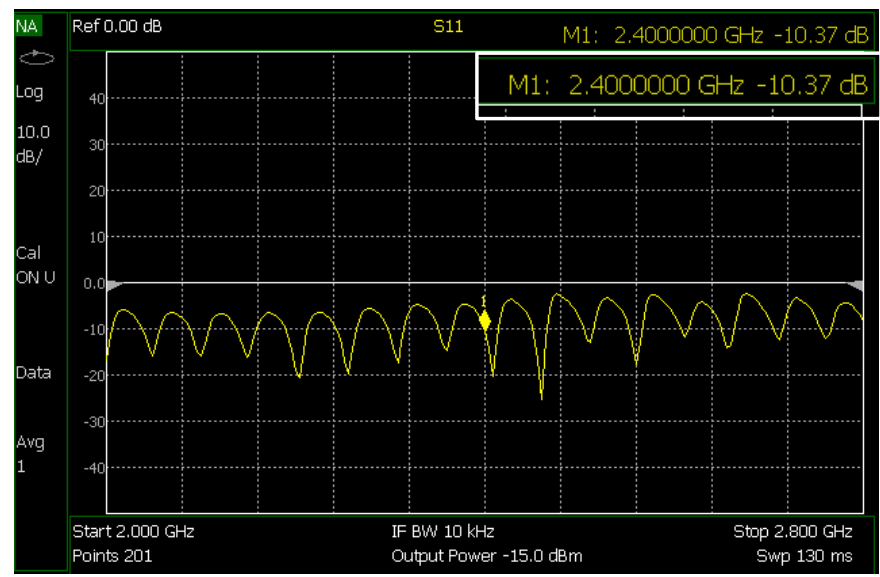

Fig. 7 Return loss.

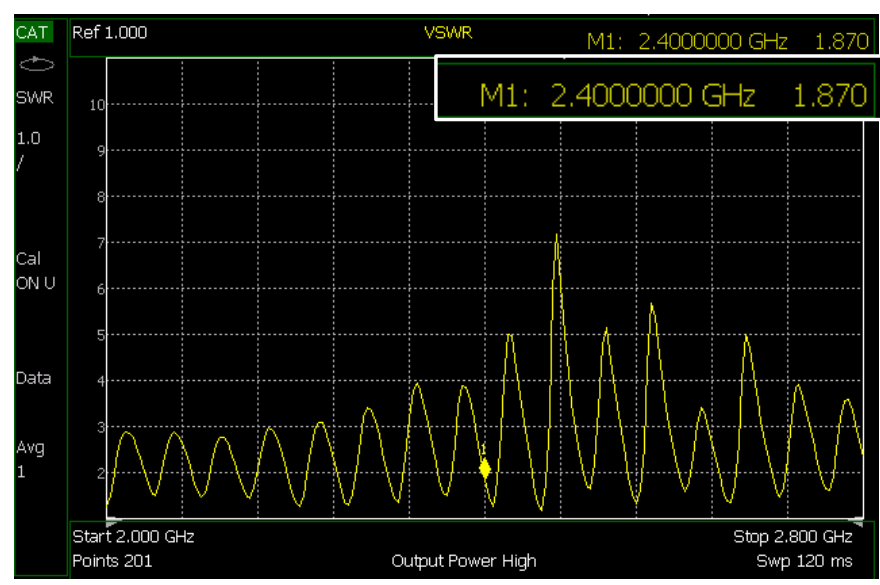

Fig. 8 VSWR.

TABLE III

PERFORMANCES COMPARISON WITH THE OTHER RESEARCHES

\begin{tabular}{|c|c|c|c|c|}
\hline $\begin{array}{c}\text { Reference } \\
\text { Antenna }\end{array}$ & Area & Height & $\begin{array}{c}\text { S11 } \\
\text { bandwidth } \\
\text { (dB) }\end{array}$ & $\begin{array}{c}\text { Gain } \\
\text { (dB) }\end{array}$ \\
\hline$[9]$ & $0.36 \lambda_{0} \times 0.36 \lambda_{0}$ & $2.65 \lambda_{0}$ & $19 \%$ & 13 \\
\hline$[11]$ & $0.40 \lambda_{0} \times 0.40 \lambda_{0}$ & $0.52 \lambda_{0}$ & $77 \%$ & 7.5 \\
\hline$[12]$ & $0.43 \lambda_{0} \times 0.43 \lambda_{0}$ & $0.25 \lambda_{0}$ & $56 \%$ & 9.4 \\
\hline$[8]$ & $0.32 \lambda_{0} \times 0.32 \lambda_{0}$ & $1.5 \lambda_{0}$ & $15 \%$ & 12.5 \\
\hline Proposed & $0.35 \lambda_{0} \times 0.35 \lambda_{0}$ & $0.23 \lambda_{0}$ & $18 \%$ & 8.9 \\
\hline
\end{tabular}

There is a slight difference between return loss and VSWR resulted from prototype testing and simulation results. This is likely to occur because of additional losses obtained from the SMA connector, coaxial cable, and alignment error at the time of measurement.

Table III shows the comparison of performances between the proposed antennas and previous studies. The antenna dimensions shown by the area and height in Table III are measured from the antenna dimensions where $\lambda_{0}$ is the wavelength in a vacuum. The antenna proposed in this paper has smaller dimensions compared to the previous study [11]; even so, it is able to produce a higher gain of $1.4 \mathrm{~dB}$. In addition, although helix antennas with parasitic rings in other studies have higher gain, the antenna sizes are six times higher [8] and 11.5 times higher [9], while the generated bandwidths are smaller than the proposed antenna [8], [9]. In this paper, the proposed strip helix antenna's dimensions are also smaller compared to the research result in [12]. Hence, it indicates that the proposed strip helix antenna has more compact results.

\section{CONCLUSION}

The parasitic rings addition could increase gain on the strip helix antenna by $0.0201 \mathrm{~dB}$. Furthermore, this addition was also able to increase the return loss from -10.169 to $-10.366 \mathrm{~dB}$, VSWR from 1.8991 to 1.8702 , and bandwidth from $135.7 \mathrm{MHz}$ to $431.9 \mathrm{MHz}$. On the other hand, the ground plane sizereduction decreased the gain instead.

\section{REFERENCES}

[1] S.S. Tambe, "Wireless Technology in Networks," International Journal of Scientific and Research Publications, Vol. 5, No. 7, pp. 5-7, 2015.

[2] A. Chaudhary, N. Pundir, and P. Goel, "Telecommunication Technologies," Advance in Electronic and Electric Engineering, Vol. 3 , No. 4, pp. 421-426, 2013.

[3] S. Kovar, H. Urbancokova, J. Valouch, M. Adamek, and V. Mach, "Helical Antenna Design for Image Transfer," International Journal of Applied Engineering Research, Vol. 12, No. 14, pp. 4741-4746, 2017.

[4] J.D. Kraust, "The Helical Antenna," Proc. IRE, Vol. 37, No. 3, pp. 263 272. 1949.

[5] S. Ozman, A.H. Shah, S. Ali, S.K. Selvaperumal, and V. Thangsamy, "Gain Enhancement of Axial Mode Helical Antenna for UAV Applications," 2015 6th International Conference on Intelligent Systems, Modelling and Simulation, 2015, pp. 237-241.

[6] Á. Palomares-caballero, P. Padilla, A. Alex-amor, and J. Valenzuela-vald, "Twist and Glide Symmetries for Helix Antenna Design and Miniaturization. Symmetry," Symmetry, Vol. 11, No. 3, paper 349, pp. 1 14, 2019.

[7] N. Ripin, A.A. Sulaiman, N.E.A. Rashid, and M.F. Hussin, "Design and Analysis of Defected Ground Structure (DGS) in Normal Mode Helical Antenna," 2014 IEEE Symposium on Wireless Technology and Applications (ISWTA), 2014, pp. 170-175.

[8] J. Kim, S.H. Cha, Y. Yoon, J. Ryu, and J.S. Choi, "Axial Mode Helical Antenna with Circular Parasitic Rings for Gain Enhancement," 2017 International Symposium on Antennas and Propagation (ISAP), 2017, pp. 2-3.

[9] L. Liu, Y. Li, Z. Zhang, and Z. Feng, "Compact Helical Antenna with Small Ground Fed by Spiral-Shaped Microstrip Line," Electronics Letters, Vol. 50, No. 5, pp. 4-5, 2014

[10] J.N. Mei, D.W. Ding, and G. Wang, "Design of Compact Wideband Circularly Polarized Conical Helix," International Conference on Computer Information Systems and Industrial Applications (CISIA), 2015, pp. 139-141.

[11] X. Tang, B. Feng, and Y. Long, "The Analysis of a Wideband StripHelical Antenna with 1.1 Turns," International Journal of Antennas and Propagation, Vol. 2016, pp. 1-7, 2016.

[12] X. Tang, Y. He, and B. Feng, "Design of a Wideband Circularly Polarized Strip-Helical Antenna with a Parasitic Patch," IEEE Access, Vol. 4, pp 7728-7735, Nov. 2016

[13] H. Oraizi and R. Pazoki, "Wideband Circularly Polarized Aperture-fed Rotated Stacked Patch Antenna," IEEE Trans. Antennas Propag., Vol. 61, No. 3, pp. 1048-1054, Mar. 2013.

[14] A. Motevasselian, A. Ellgardt, and B.L.G. Jonsson, "A Helix Excited Circularly Polarized Hollow Cylindrical Dielectric Resonator Antenna," IEEE Antennas Wireless Propag. Lett., Vol.12, pp. 535-538, 2013.

[15] S.-P. Pan, J.-Y. Sze, and P.-J. Tu, "Circularly Polarized Slot Antenna with a Largely Enhanced Axial Ratio Bandwidth," IEEE Antenna Wireless Propag. Lett., Vol. 11, pp. 969-972, 2012.

[16] Y. He, W. He, and H. Wong, "A Wideband Circularly Polarized Crossdipole Antenna," IEEE Antennas Wireless Propag. Lett., Vol. 13, pp. 67 70,2014 
[17] Z. Chen and Z. Shen, "Planar Helical Antenna of Circular Polarization," IEEE Trans. Antennas Propag., Vol. 63, No. 10, pp. 4315-4323, Oct. 2015.

[18] S. Fu, Q. Kong, S.-J. Fang, and Z. Wang, "Optimized Design of Helical Antenna with Parasitic Patch for L-band Satellite Communications," Prog. Electromagn. Res. Lett., Vol. 44, pp. 9-13, 2014.

[19] L. Li, Y. Zhang, J. Wang, W. Zhao, S. Liu, and R. Xu, "Bandwidth and Gain Enhancement of Patch Antenna with Stacked Parasitic Strips Based on LTCC Technology," International Journal of Antennas and Propagation, Vol. 2014, pp. 1-5, 2014.
[20] T. Sabapathy, M.F. Jamlos, M. Jusoh, and M.I. Jais, "Gain Enhancement of Circular Patch Antenna Using Parasitic Ring," 2013 IEEE Antennas and Propagation Society International Symposium (APSURSI), 2013, pp. 1836-1837.

[21] R. Sahoo and D. Vakula, "International Journal of Electronics and Communications (AEÜ) Gain Enhancement of Conformal Wideband Antenna with Parasitic Elements and Low Index Metamaterial for WiMAX Application," AEUE - International Journal of Electronics and Communications, Vol. 105, pp. 24-35, 2019. 